\title{
Editorial: CouldSpeciationAcross Evolution be Governed by Genetic Switch Codes at Short Tandem Repeats?
}

Citation: Ohadi M. Could Speciation Across Evolution be Governed by Genetic Switch Codes at Short Tandem Repeats?. Iranian Rehabilitation Journal. 2017; 15(1):3-4. https://doi.org/10.18869/nrip.irj.15.1.3

: https://doi.org/10.18869/nrip.irj.15.1.3

The field of rehabilitation and social welfare may seem irrelevant to the issues concerning evolution. However, many of the disorders leading to severe disability and dependence on rehabilitation measures belong to the category that is human-specific. In this category, neuropsychiatric and movement disorders may be of particular interest. Understanding the basic mechanisms underlying those disorders promise to pave the way for better therapeutic and interventional measures.

Numerable events are crucial to an evolutionary path leading to a particular species. However, how many of those events have been decisive, and were of prime importance? In other words, were there only a few crucial events that triggered the successive evolutionary events, exemplified by the differential evolution of the AMY1 gene in agricultural vs. hunter-gatherer humans [1], or highly restricted initial divergence in butterfly hybridization models [2].

Short Tandem Repeats (STRs) may provide additional models for those hypothetical few events that might have resulted in speciation in evolutionary/adaptive terms. And if

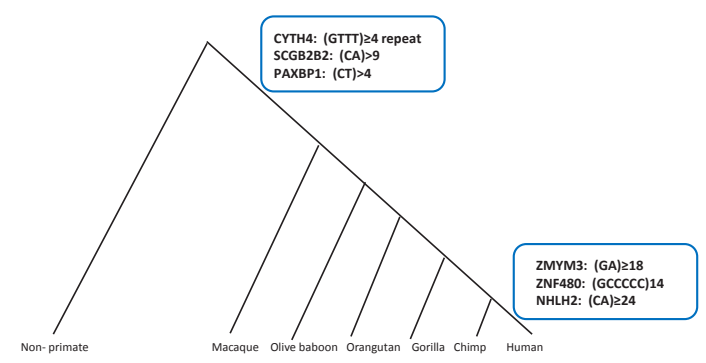

Iranian Rehabilitation Journal Figure 1. Proposed evolutionary model for the contribution of short tandem repeats (STRs) to speciation. The nature of STRs to expand or contract makes them an ideal source of evolutionary adaptation and speciation. The mathematical combination of certain STRs might have been used as spectacular codes for the evolution of different species, exemplified by a few STRs in the promoter sequence of certain genes such as CYTH4, ZMYM3, SCGB2B2, and PAXBP1. they could, would they consist of specific codes at different evolutionary crossroads? To this end, STRs have been identified, expansion or identical co-occurrence of which appear to be decisive in specific evolutionary divergence points [3-6] (Figure 1). In those instances, the threshold number of repeats for each STR seems to be crucial to species divergence (i.e. a mathematical switch code combination of STRs). The present editorial is intended to stir up thoughts, research, and commentary in this largely untouched area of evolutionary biology.

* Corresponding Author:

Mina Ohadi, MD, PhD

Address: Iranian Research Center on Aging, University of Social Welfare and Rehabilitation Sciences, Tehran, Iran.

E-mail: ohadi.mina@yahoo.com; mi.ohadi@uswrac.ir

\section{References}

[1] Perry GH, Dominy NJ, Claw KG, Lee AS, Fiegler H, Redon $\mathrm{R}$, et al. Diet and the evolution of human amylase gene copy number variation. Nature Genetics. 2007; 39(10):1256-60. PMCID: PMC2377015

[2] Kronforst MR, Hansen ME, Crawford NG, Gallant JR, Zhang W, Kulathinal RJ, et al. Hybridization reveals the evolving genomic architecture of speciation. Cell Reports. 2013; 5(3):666-77. doi: 10.1016/j.celrep.2013.09.042

[3] Mohammadparast S, Bayat H, Biglarian A, Ohadi M. Exceptional expansion and conservation of a CT-repeat complex in the core promoter of PAXBP1 in primates. American Journal of Primatology. 2014; 76(8):747-56. doi: 10.1002/ajp.22266

[4] Nikkhah M, Rezazadeh M, Khorram Khorshid HR, Biglarian A, Ohadi M. An exceptionally long CA-repeat in the core promoter of SCGB2B2 links with the evolution of apes and Old World monkeys. Gene. 2016; 576(1):109-14. doi: 10.1016/j. gene.2015.09.070

[5] Ohadi M, Valipour E, Ghadimi-Haddadan S, Namdar-Aligoodarzi P, Bagheri A, Kowsari A, et al. Core promoter short tandem repeats as evolutionary switch codes for primate speciation. American Journal of Primatology. 2015; 77(1):34-43. 
[6] Rezazadeh M, Gharesouran J, Mirabzadeh A, Khorram Khorshid HR, Biglarian A, Ohadi M. A primate-specific functional GTTT-repeat in the core promoter of CYTH4 is linked to bipolar disorder in human. Prog Progress in NeuroPsychopharmacology \& Biological Psychiatry. 2015; 56:161-7. doi: 10.1016/j.pnpbp.2014.09.001 